\title{
Ideologia nas Opiniões de Estudantes de Ensino Médio sobre Sucesso no Trabalho
}

\author{
João Wachelke \\ Universidade Federal de Uberlândia, Uberlândia, MG, Brasil.
}

\begin{abstract}
Resumo: As opiniões e crenças de adolescentes sobre o sucesso no trabalho constituem um contexto psicossocial pertinente para identificar indícios de efeitos ideológicos, já que se referem às expectativas e ao planejamento das atividades que inscreverão ou inscrevem cada pessoa no espaço social das relações com meios de produção. $O$ estudo avaliou indicadores de opinião sobre sucesso no trabalho da Pesquisa de Percepções Sociais de Estudantes Uberlandenses (Perseu) de 2013, realizada junto a 736 estudantes da segunda série do ensino médio de três escolas. A análise de dados consistiu em estatísticas descritivas das opiniões por meio de cruzamentos de frequências a partir de estratos de renda familiar e escolaridade da mãe, e análise de correspondências múltiplas. Os resultados indicaram tendência de consenso na amostra a respeito da meritocracia como princípio vigente para garantir o sucesso no trabalho, bem como maior adesão dos estratos de renda e escolaridade inferiores a opiniões recomendando a obediência a chefes e normas de empresas. A discussão centra-se no processo de naturalização ideológica e sua relação com os consensos sociais e busca explicar o perfil de opinião dos estratos desfavorecidos a partir de tendências psicológicas de justificação do sistema e da avaliação racional da restrição de possibilidades de vida.
\end{abstract}

Palavras-chave: Ideologia, Trabalho, Meritocracia, Adolescentes, Opiniões.

\section{Ideology in the Opinions of Secondary School Students on Success at Work}

The opinions and beliefs of adolescents regarding success at work constitute a relevant psychosocial context to identify evidence of ideological effects, since they refer to the expectations and planning of activities that will insert or insert each person in the social space of the relationships with production means. The study has assessed opinion indicators on success at work from the 2013 Uberlandia Students' Social Perceptions Survey (Perseu), carried out with 736 secondary school students from three schools. Data analysis consisted in descriptive statistics of opinions through frequency crosstabs from family income and mother education strata, as well as multiple correspondence analysis. Results indicated a consensus trend in the sample concerning meritocracy as a ruling principle to ensure success at work and higher agreement from lower income and education strata with opinions recommending the obedience to bosses and firm norms. Discussion focuses on the ideological naturalization process and its relationship with social consensus and aims at explaining the opinion profile of disadvantaged strata by means of psychological trends of system justification and rational assessment of life possibilities.

Keywords: Ideology, Work, Meritocracy, Adolescents, Opinions. 


\title{
La Ideología en las Opiniones de Estudiantes de Secundaria Acerca del Éxito en el Trabajo
}

\begin{abstract}
Resumen: Las opiniones y creencias de los adolescentes sobre el éxito en el trabajo constituyen un contexto psicosocial relevante para identificar la evidencia de efectos ideológicos, ya que se refieren a las expectativas y a las actividades de planificación que inscribirán o inscriben a cada persona en el espacio social de las relaciones con los medios de producción. El estudio evaluó indicadores de opinión sobre el éxito en el trabajo de la Investigación de las Percepciones Sociales de Estudiantes de Uberlandia (PERSEU) de 2013, llevada a cabo con 736 estudiantes de escuela secundaria de tres escuelas. El análisis de los datos consistió en estadística descriptiva de opiniones por tablas de frecuencia de estratos de ingreso familiar y educación de la madre, y en un análisis de correspondencias múltiples. Los resultados indicaron tendencia de consenso en la muestra respecto a la meritocracia como principio para asegurar el éxito en el trabajo y una mayor adherencia de aquellos con menores ingresos y estratos de educación a opiniones que recomiendan la obediencia a los jefes y a las normas de las empresas. La discusión se centra en el proceso de naturalización ideológica y su relación con el consenso social, y trata de explicar el perfil de opinión de los estratos desfavorecidos por las tendencias psicológicas de justificación del sistema y evaluación racional de la restricción de las posibilidades de vida.
\end{abstract}

Palabras clave: Ideología, Trabajo, Meritocracia, Adolescentes, Opiniones.

O trabalho é a principal fonte de renda da maior parte da população brasileira. À exceção de uma minoria capaz de garantir suas condições de vida a partir de investimentos, herança ou aluguéis, os trabalhadores vendem sua força de trabalho para obter um salário e garantir seu sustento e, eventualmente, de suas famílias. Conforme a Pesquisa Nacional por Amostra de Domicílios referente ao $1^{\circ}$ trimestre de 2017, 61,6\% das pessoas com mais de 14 anos de idade estavam na força de trabalho, e 56,9\% possuíam ocupação durante a realização da pesquisa. Dos mais de 90 milhões de brasileiros ocupados, $68 \%$ eram empregados, $24,9 \%$ trabalhavam por conta própria, e somente 4,6\% eram empregadores (IBGE, 2017).

Aremuneração do trabalho está diretamenteligada à possibilidade de viver bem e atingir metas pessoais, já que permite adquirir bens e serviços essenciais que proporcionam conforto. Mas há grandes discrepâncias nos seus valores, associadas a fatores como o nível de treinamento - o que geralmente equivale a dizer credenciais educacionais - exigido por cada cargo, à possibilidade de um emprego gerar riquezas para terceiros ou à dificuldade de encontrar pessoas capazes de realizar determinado trabalho, dentre outros fatores. A análise de Aage Sørensen (2005) é elucidativa nesse ponto: ativos econômicos valiosos, seja na forma de propriedades ou de qualificações no mercado de trabalho, geram um excedente de riqueza a seus detentores, especialmente quando há limitações para que a população atinja os maiores níveis de escolaridade ou altos custos para adquirir uso de recursos produtivos.

Marcio Pochmann e seus colaboradores (Pochmann, Amorim, Guerra, \& Aldrin, 2009) propõem que sejam consideradas como pertencentes a uma classe proprietária as pessoas com ativos tangíveis e intangíveis como empresas, imóveis, ativos financeiros e altos níveis de escolaridade. Trabalhadores sem ativos valiosos desse tipo encontram-se em situação desfavorável para melhorar sua situação econômica. E constituem a maioria da população brasileira: conforme dados apresentados por Pochmann (2012, p. 27-29), em 2009 mais da metade dos brasileiros ocupados no trabalho tinham remuneração de até 1,5 salários-mínimos, e mais de $80 \%$, até 3 salários-mínimos.

As chances individuais de uma remuneração melhor, sem reestruturação do mercado de trabalho e maior igualdade salarial, situam-se na busca por empregos valorizados ou aquisição de ativos produtivos. A segunda opção é inviável sem capital, e a primeira passa pela obtenção de credenciais educacionais. Não é tarefa fácil, dada a desigualdade de 
oportunidades educacionais no Brasil. Ribeiro (2011), em análise de dados de 2008 da Pesquisa Dimensões Sociais da Desigualdade, obteve resultados que indicaram que a existência de riqueza familiar, o status ocupacional elevado dos pais e a frequência a escolas particulares ou federais favorecem um percurso escolar mais longo, com mais anos de estudo em comparação com indivíduos de famílias desprovidas de riqueza, com pais de baixo status ocupacional e que frequentaram escolas públicas.

Mas se é pouco provável que a maioria da população, desprovida de ativos econômicos ou qualificações educacionais valiosas, consiga atingir níveis de renda que permitam conforto, como a sociedade permanece sem conflitos fortes entre setores privilegiados e a maioria trabalhadora? O que garante a coesão social frente à contradição de uma minoria que detém a maior parte dos recursos e uma massa com rendimentos humildes?

Uma parte da resposta provavelmente está no poder das ideologias. Primeiramente, devo esclarecer que é impossível fornecer uma dimensão consensual do que seja ideologia; os cientistas sociais apropriaram-se desse conceito conforme os posicionamentos de seus autores, moldando-o de diferentes maneiras e direcionando-o para elucidar as questões sociais que lhes pareceram essenciais. Para autores como Antoine Destutt de Tracy (1801) e Karl Mannheim (1987), ideologias têm uma conotação neutra. Para o primeiro, seria a ciência de formação das ideias, o conhecimento supostamente verdadeiro sobre os processos de pensamento. Para o segundo, ideologia é o sistema de pensamento de um grupo histórico-cultural ou de uma época. É mais conhecida a vertente da ideologia como uma falsa consciência ou conjunto de ideias que mistificam a realidade, com forte influência marxista. Em A ideologia alemã de Karl Marx e Friedrich Engels (2009), a ideologia refere-se ao saber de filósofos que na verdade constituem ideias da classe dominante que invertem as relações da realidade, ocultando a verdade material da luta de classes. Posteriormente, n'O Capital (Marx, 1996), a ideologia diz respeito à alienação real por que passam os trabalhadores, escravizados pelas próprias mercadorias produzidas por eles. Por sua vez, Althusser (1996) considera que o conhecimento ideológico é produzido e propagado em práticas ligadas a instituições sociais, os aparelhos de Estado, que reproduzem as relações sociais capitalistas de produção, chancelando a exploração de classes dominadas pelas dominantes. São apenas as linhas gerais de algumas das definições clássicas de ideologia, e é perceptível a dificuldade de chegar a algum acordo a respeito das características centrais do conceito.

Gerring (1997) sugere que a maior utilidade do conceito está em atrelá-lo a finalidades específicas de pesquisa. Nesse sentido, para avançar no enquadramento da relação entre ideologia e as questões ligadas ao mundo do trabalho, tomo como ponto de partida a concepção de Thompson, para quem ideologia corresponde às: “...maneiras como o sentido serve para estabelecer e sustentar relações de dominação” (2011, p. 76). Assim, para Thompson, as ideologias são explicações sobre o mundo que tomam o lugar de verdades para as pessoas e agem na manutenção de relações desiguais de poder. Para o autor, a ideologia é um conhecimento falso, uma ilusão que esconde como as coisas são de fato.

Contudo, se as ideologias são sempre parciais, como qualquer conhecimento sobre a vida social, isso não quer dizer que sejam falsas. Žižek (1996) apresenta um contraponto lembrando que, inclusive, as ideologias podem ser verdadeiras, isto é, conter elementos "corretos": o importante é que o conhecimento ideológico sirva para legitimar relações de dominação, e que para ser eficaz oculte a lógica dessa dominação. Žižek também apresenta outra armadilha: ao declarar uma ideologia como falsa e proclamar outra versão como verdadeira, caímos novamente na ideologia e sua falsidade. Portanto, a crítica da ideologia deve permanecer em constante tensão e avaliar suas características e implicações, resistindo em colocar algo em seu lugar, o que apenas desembocaria noutras formas de conhecimento ideológico.

Particularmente, proponho trabalhar com a concepção de ideologia como uma interpretação sobre a vida social que é capaz de descrever a sociedade e levar à ação sobre ela. Além disso, a ideologia deve ser entendida aqui como interpretação que sempre possui efeitos políticos; não faço restrição em termos de sua função ser apenas a conservação - manutenção de relações de poder favoráveis aos grupos dominantes -, admitindo, portanto, também visões de mundo transformadoras do status quo. De todo modo, no presente caso o papel conservador de ideologias ligadas ao sucesso no trabalho é que se mostra pertinente.

Temas como sucesso no trabalho e vida profissional prestam-se particularmente bem a discursos ideológicos. Assim, em vez de promover uma redistribuição de recursos econômicos para a população que não tem acesso a eles, para melhorar suas potencia- 
lidades de renda; ou de universalizar o acesso à educação de boa qualidade para aumentar as oportunidades de inserções profissionais futuras dignas em empregos com altas remunerações, é possível promover a crença de que, por exemplo, quem se dedica com afinco ao trabalho obterá o sucesso profissional, isto é, que com esforço quaisquer barreiras para obter um bom emprego, maiores ou menores, são superáveis. Ou, então, que o sucesso no trabalho é uma possibilidade ao alcance de pessoas de todas as origens.

Não é falso; são possibilidades existentes, há inúmeras histórias de pessoas que começaram na pobreza e gradativamente galgaram as escadas na hierarquia social devido ao bom desempenho em suas funções. Mas essas crenças ocultam informações adicionais: as baixas probabilidades efetivas de chegar a esses desfechos a partir de situações iniciais desfavoráveis. Ou seja, são crenças que descrevem percursos possíveis, mas improváveis. E é aí que desponta sua natureza ideológica: constituem meias verdades, ao não especificar suas condições de validade, dado que não são universais. $\mathrm{E}$ a adesão a essas crenças fornece esperança de um futuro melhor, estimula o conformismo de que com trabalho disciplinado e paciência será possível ter sucesso no trabalho e uma boa renda. A ideologia contribui então para manter a reprodução da sociedade, de modo conveniente aos estratos que ocupam posições favoráveis, pois reduz atritos e contestações a esquemas de distribuição de recursos vigentes. Ao domesticar, controlar, apaziguar os dominados, garante aos dominantes menos resistência para perpetuar suas vantagens. A ideologia assegura o exercício do poder simbólico, que, nos termos de Bourdieu (1977), é o poder legitimado, eficaz por exercer efeitos sem ser reconhecido como violência. Nos casos dos exemplos acima, a eventual impossibilidade de uma pessoa garantir boas condições de trabalho passa a ser explicada por inadequações pessoais, incompetência, falta de merecimento, relegando aos perdedores do jogo social a culpa por seu fracasso.

Nesta pesquisa, a população de interesse para investigar opiniões sobre sucesso no trabalho é a de adolescentes, estudantes de ensino médio. Há algumas pesquisas sobre opiniões e crenças de adolescentes brasileiros sobre trabalho. Luciana Thomé e suas colaboradoras (Thomé, Telmo, \& Koller, 2010) realizaram levantamento junto a mais de sete mil jovens com 14 a 24 anos de idade de diversas cidades brasileiras, trabalhadores e não trabalhadores. Os participantes da pesquisa relataram um entendimento do trabalho associado fortemente à obtenção de dinheiro que viabiliza a vida de cada um. Além disso, o trabalho foi percebido ligado à honra e à produção de coisas úteis. De modo semelhante, Gênesis Sobrosa e colaboradores (Sobrosa, Camerin, Perrone, \& Dias, 2013) realizaram estudo com 200 estudantes de ensino médio de escolas públicas de Santa Maria, RS, e observaram o trabalho associado a aspectos positivos e concebido como meio de ter independência financeira. Já Denize Oliveira e colaboradores (Oliveira, Fischer, Amaral, Teixeira, \& Sá, 2005), em pesquisa com mais de 700 estudantes de uma escola pública de São Paulo, observaram uma representação ambígua do trabalho. Dentre os aspectos positivos, identificaram a possibilidade de obter dinheiro, o fato de constituir atividade digna e moralmente bem avaliada e o amadurecimento e responsabilidade associados ao trabalho. Mas, ao mesmo tempo, o trabalho foi percebido como algo cansativo e como necessidade para sobreviver. Considerando esses três estudos, emerge uma percepção sistemática predominante que ressalta sua associação com a sobrevivência e viabilização de objetivos pessoais, já que, para esses estudantes, frequentemente de classes populares, somente a partir da venda da força de trabalho é possível ter acesso aos recursos financeiros para atingir objetivos pessoais atrelados ao sustento pessoal. Mas o que pensam sobre como ser bem-sucedido no trabalho? Respostas aludindo à responsabilidade, esforço e amadurecimento fornecem indícios da crença de que vige a meritocracia nos contextos de trabalho e que a conformidade às normas desses contextos é recompensada. Contudo, os estudos mencionados não abordam esse tipo de pensamento especificamente.

As opiniões e crenças de adolescentes sobre o sucesso no trabalho constituem um contexto psicossocial pertinente para identificar indícios de efeitos ideológicos, já que se referem às expectativas e ao planejamento das atividades que inscreverão ou inscrevem cada pessoa no espaço social das relações com meios de produção. A posição familiar em termos de coordenadas quanto às hierarquias sociais - classe, cor da pele, gênero e quaisquer outras divisões associadas a poder social -, está associada a probabilidades diferentes de um adolescente ocupar um posto de trabalho de alto nível técnico ou manual de rotina; de trabalhar com um emprego remunerado ou voltar-se para o trabalho doméstico; de ter rendimentos baixos ou altos, e assim por diante. Isso diz respeito em boa parte aos recursos materiais que podem ser mobi- 
lizados pelos pais ou responsáveis na formação do estudante, à distância cultural entre suas condições de vida e o desempenho que é valorizado em instituições educacionais que fornecem credenciais para os melhores postos de trabalho.

Para estudantes de ensino médio, pensar acerca de temas ligados ao trabalho diz respeito a projetar sua existência no futuro, tanto em termos de cenários prováveis para si quanto de delinear estratégias viáveis para inserir-se na vida profissional. O posicionamento favorável ou desfavorável em relação a opiniões com conteúdo ideológico acerca do sucesso no trabalho fornece evidências para verificar se é plausível encontrar relações entre posição na sociedade e opiniões, indicando tanto sua percepção do mundo de um modo que lhes seja adaptativo como seus rumos para mover-se nesse mundo, tido como legítimo ou não.

A presente pesquisa é exploratória e tem por objetivo caracterizar as opiniões de estudantes de ensino médio de Uberlândia, cidade de médio porte da região do triângulo em Minas Gerais, acerca de opiniões sobre o sucesso profissional, levando em conta as diferenças nas posições sociais que esses estudantes ocupam. Diferencio as posições sociais em termos de volume e tipo de recursos econômicos e culturais, isto é, faço uso da contribuição de Bourdieu (1986) a respeito das propriedades de capital econômico e capital cultural. O capital econômico diz respeito à posse de ativos econômicos; no presente caso, o acesso à renda familiar. As classes de renda podem não ser o melhor referencial para captar mobilidade social e estruturas de desigualdade - na sociologia, predominam classificações de posições de trabalho e suas relações com os meios de produção - ver, por exemplo, Wright (2005) -, mas inversamente podem mostrar-se mais sensíveis para capturar correspondências entre posições sociais e mentalidades dos ocupantes dessas posições, uma vez que estes tenham sido socializados de acordo com divisões organizadas conforme essa lógica.

Já o capital cultural refere-se ao acesso a conhecimentos culturais valorizados socialmente que permitem obter vantagens sociais, como, por exemplo, bons empregos. No presente estudo, operacionalizo a propriedade de capital cultural a partir do grau de escolaridade materna; há evidências de que a escolaridade da mãe prevê a escolarização dos filhos melhor que a escolaridade do pai (conforme Buchmann, 2002).

Finalmente, avalio opiniões sobre sucesso no trabalho que expressem aspectos ideológicos a respeito do entendimento da meritocracia como princípio determinante dos desfechos positivos ou negativos em termos de recompensas profissionais e da conformidade às chefias e lideranças do trabalho como estratégia para garantir o sucesso. Interessam-me opiniões ligadas a esses aspectos porque eles endossam o sistema de distribuição de recompensas e o alinhamento individual a esse sistema. No que diz respeito à adesão ao pensamento de que a meritocracia é a regra em voga, ela estimula a aceitação do sistema de recompensas ainda que em diversas situações o mérito não seja recompensado, ou fique em segundo plano a constatação de que as trajetórias formativas e culturais diferentes das pessoas impedem condições equivalentes de concorrência e, portanto, pré-decidem desfechos. Por sua vez, o pensamento de conformidade às chefias e normas de trabalho parece a estratégia mais sensata frente às condições assimétricas em que muitos trabalhadores se encontram, e também inibe por mudanças ou questionamento de relações injustas.

\section{Método}

\section{Participantes}

Inicialmente, houve um total de 740 participantes, mas excluí do banco de dados um caso sem informação de sexo e outros três que não traziam dados sobre escolaridade de nenhum dos pais. A amostra conteve então 736 participantes, dos quais 379 $(51,4 \%)$ eram do sexo feminino. A média de idade foi de 16 anos, com desvio-padrão de 0,87 anos. Dos participantes, 53,2\% estavam matriculados numa escola particular e os restantes em duas escolas públicas (25,8\% e 20,9\%, respectivamente).

Considerando o Critério de Classificação Econômica Brasil (CCEB) vigente ao ano de 2013 (ABEP, 2013), 247 participantes (33,6\%) pertenciam ao estrato econômico A (equivalente a renda média familiar bruta de $\mathrm{R} \$ 9.263$, na base de dados LSE 2011), 188 (25,5\%), ao estrato B1 (R\$ 5.241 de renda), $190(25,8 \%)$, ao estrato B2 (R\$ 2.654) e $111(15,1 \%)$ faziam parte do estrato econômico C (fusão de classe $\mathrm{C} 1$, renda média de $\mathrm{R} \$ 1.685$, e $\mathrm{C} 2, \mathrm{R} \$ 1.147)$. No que diz respeito à escolaridade da mãe, $84(11,4 \%)$ ou não haviam estudado ou haviam cursado no máximo a $4^{\text {a }}$ série, o que chamo de Ensino Fundamental 1; 116 $(15,7 \%)$ completaram até a $8^{\text {a }}$ série, o que denomino Ensino Fundamental 2; 204 (27,7\%) concluíram o ter- 
ceiro ano do científico, hoje equivalente ao Ensino Médio; e 332 (45\%) concluíram o Ensino Superior, isto é, tinham diploma universitário ${ }^{1}$.

Um cruzamento baseado nas variáveis de estrato econômico (operacionalização de capital econômico) e escolaridade da mãe (operacionalização de capital cultural) fornece uma terceira variável que permite avaliar possíveis interações entre os dois tipos de capital, que denomino posição social. Desse modo, fiz nova categorização com os participantes classificados nos estratos econômico A e B1 como tendo alto capital econômico (A), e codifiquei os participantes dos estratos B2 e C1 como capital econômico baixo (B). No que diz respeito à escolaridade da mãe, considerei as categorias de capital cultural superior (S, Ensino Superior), capital cultural médio (M, Ensino Médio) e capital cultural baixo (B, Fundamental 1 e 2). As combinações das duas propriedades geraram seis categorias, em que a primeira letra diz respeito ao capital econômico e a segunda, ao cultural. Temos então as posições AS (39,2\% da amostra), AM (13\%), AB (6,8\%), BS (5,8\%), BM (14,7\%) e BB (20,4\%). Há associação na amostra entre os dois tipos de capital, que tendem a ocorrer simultaneamente em níveis elevados ou baixos.

\section{Instrumento}

$\mathrm{O}$ instrumento utilizado foi um questionário autoaplicado da Pesquisa de Percepções Sociais de Estudantes Uberlandenses de 2013 (Perseu-2013), que solicitava avaliações sobre a importância de valores pessoais (primeira parte) valores da sociedade (segunda parte), opiniões sobre sucesso no trabalho (terceira parte), crenças sobre justiça (quarta parte) e informações sociodemográficas e de acesso a bens de consumo e serviços e escolaridade dos pais (quinta parte). Para este trabalho, a parte relevante é a terceira, com dez sentenças, aqui tratadas como indicadores de opinião ( $s 1$ a $s 10$ ), apresentados na Tabela 1. Para cada uma das frases, o respondente tinha três opções de resposta: concordo, indeciso e discordo.

A maior parte das sentenças é compatível com ideologias conservadoras, na medida em que sustentam nexos causais de sucesso ou fracasso profissional em características de desempenho e conduta individual como obediência ou dedicação ao empregador $(s 4)$ e normas da instituição de trabalho $(s 2, s 5)$, geração de novas ideias ( $s 1$ ), esforço próprio $(s 3, s 5, s 7, s 8$, $s 10$ ), paciência e disciplina $(s 6, s 7)$. Ou seja, o arranjo dos esquemas de distribuição de oportunidades no trabalho, de caráter social, não é contestado por essas afirmativas. Há ainda uma frase no sentido contrário, que ressalta que contatos pessoais são importantes para conseguir bons empregos ( $(s 9)$.

As informações sociodemográficas solicitadas pelo questionário foram sexo e idade. $\mathrm{O}$ formato de resposta aos bens de consumo e serviços e escolaridade do pai foi compatível com o CCEB vigente ao ano de 2013 (Associação Brasileira de Empresas de Pesquisa [ABEP], 2013), gerando escores para enquadrar cada respondente nos estratos econômicos já mencionados. O questionário também incluiu uma questão sobre a escolaridade da mãe. Para o cálculo do CCEB, esta foi considerada em nove casos em que não havia dados sobre a escolaridade do pai.

\section{Procedimento}

O Comitê de Ética em Pesquisa da Universidade Federal de Uberlândia aprovou o projeto em que se insere a pesquisa aqui relatada no parecer $\mathrm{n}^{\circ} 379.510$ de 2013. A Perseu-2013 teve coleta de dados no ano de 2013 em três escolas de Uberlândia, Minas Gerais, duas delas da rede pública e uma particular. A amostragem foi não probabilística, determinada pela disponibilidade das instituições contatadas em contribuir para o projeto. Após anuência dos dirigentes das instituições e concordância dos responsáveis legais pelos estudantes, expressa através de Termos de Consentimento Livre e Esclarecido, a equipe de pesquisa, formada por mim e por três assistentes treinados para a coleta, aplicou questionários junto a todas as turmas da $2^{\text {a }}$ série do Ensino Médio dessas instituições. A situação de aplicação foi coletiva, e os participantes responderam aos questionários individualmente. A equipe de pesquisa sanou quaisquer dúvidas de procedimento ou compreensão da atividade.

Realizei análises descritivas de frequência, considerando as proporções, expressas em percentuais, de respostas de concordância, indecisão e discordância para cada um dos indicadores de opinião. Além das proporções gerais, obtive cruzamentos a partir das variáveis de estrato econômico, escolaridade da mãe, e

\footnotetext{
${ }^{1}$ Houve um caso em que não havia informação sobre a escolaridade da mãe, mas havia dados sobre a escolaridade paterna. Optei por reproduzir esse valor na escolaridade da mãe para não perder o participante.
} 
Tabela 1

Conteúdo dos Indicadores de Opinião sobre Trabalho.

\begin{tabular}{ll}
$\begin{array}{l}\text { Indicador de } \\
\text { opinião }\end{array}$ & \multicolumn{1}{c}{ Conteúdo } \\
\hline s1 & Para conseguir sucesso no mundo do trabalho, o mais importante é ter grandes ideias. \\
s2 & O sucesso profissional vem para quem obedece às normas da empresa em que trabalha. \\
s3 & Disciplina e trabalho duro são as principais chaves para o sucesso profissional. \\
s4 & Se as pessoas obedecerem a seus chefes, um dia seu trabalho será reconhecido. \\
s5 & Quem “veste a camisa” da empresa onde trabalha logo subirá na carreira. \\
s6 & É preciso contentar-se com salários baixos no início da vida, para depois crescer aos poucos. \\
s7 & Se as pessoas trabalharem duro, um dia seu trabalho será reconhecido. \\
s8 & O que leva a pessoa a ter um ótimo emprego é o merecimento por seu desempenho. \\
s9 & Indicações e contatos levam as pessoas a terem os melhores trabalhos. \\
s10 & Qualquer um pode vencer na vida profissional com dedicação e esforço. \\
\hline
\end{tabular}

posição social. Posteriormente, realizei uma análise de correspondências múltiplas (Greenacre, 2007; Le Roux, \& Rouanet, 2010) com a finalidade de sintetizar as principais associações entre as respostas dos indicadores de opinião tomados em conjunto. A projeção dos perfis da tabela indicadora cruzando indivíduos e todas as variáveis de opinião simultaneamente num plano gráfico permite visualizar com mais facilidade as associações entre as variáveis, e é possível também projetar as posições de variáveis suplementares para ilustrar eventuais diferenças. Todas as análises foram realizadas no programa $R$ (R Core Team, 2015), com auxílio dos pacotes FactoMineR (Lê, Josse, \& Husson, 2008), factoextra (Kassambara, \& Mundt, 2016), missMDA (Josse, \& Husson, 2016) e GDAtools (Robette, 2014).

\section{Resultados}

A Tabela 2 apresenta as proporções de resposta a cada um dos indicadores de opinião. Além das proporções gerais, há as proporções associadas a cada uma das modalidades de classe econômica, escolaridade da mãe e posição social. Houve dois valores omissos relativos aos indicadores $s 2, s 7$ e $s 9$ e um valor omisso para os indicadores $s 1$ e $s 6$.

Os resultados dos indicadores $s 3$ (disciplina e trabalho duro levam ao sucesso), $s 8$ (merecimento por desempenho leva a bom emprego) e $s 10$ (qualquer um pode vencer na vida com esforço) são os que mais se aproximam de consensos na amostra, próximos a $80 \%$ de concordância, com indecisão variando de pouco mais de $7 \%$ a $11 \%$. Trata-se de opiniões alinhadas com a crença meritocrática, isto é, de que o esforço pessoal é recompensado e leva ao sucesso no trabalho, e que esse sucesso é uma via aberta para todos.

Mas há também variações: para o indicador $s 3$, os participantes com posição social de baixo capital econômico e média escolaridade da mãe são os que tiveram a proporção mais alta $(86 \%)$, contrastando com os 74\% dos participantes com alto capital econômico e mãe com curso superior. Para $s 8$, participantes com alto capital econômico tiveram taxa de concordância maiores (82\%) quando tinham mães com nível médio de escolaridade, se comparados aos percentuais dos demais de classe econômica favorável. Já entre os participantes com baixo capital econômico, foram os participantes com mães com escolaridade média e baixa que tenderam a concordar acima de $85 \%$, diferenciando-se dos participantes com mãe com nível superior ( $72 \%$ e $18 \%$ de indecisos). Para $s 10$, as baixas escolaridades maternas favorecem a tendência dos participantes com alto e baixo capital econômico a concordarem com uma visão meritocrática do sucesso no trabalho.

Dois indicadores não chegam a ser consensuais mas apresentam resultados com baixa variação nas modalidades das variáveis. $\mathrm{O}$ indicador $s 6$, voltado para a aceitação de baixos salários em fases iniciais da vida esperando progresso posterior, tem concordâncias variando entre $60 \%$ e $74 \%$. O indicador $s 7$, que afirma que o trabalho duro termina por ser reconhecido, varia principalmente entre $71 \%$ e $75 \%$. Com taxas de aceitação inferiores, $s 9$, que expressa a opinião de que são os contatos pessoais que resultam em 
Tabela 2

Distribuições de Frequências Relativas (\%) de Indicadores de Opinião sobre Sucesso Profissional Conforme as Variáveis Explicativas.

\begin{tabular}{|c|c|c|c|c|c|c|c|c|c|c|c|c|c|c|c|}
\hline \multirow{2}{*}{ CLA } & \multicolumn{3}{|c|}{ s1 } & \multicolumn{3}{|c|}{ s2 } & \multicolumn{3}{|c|}{ s3 } & \multicolumn{3}{|c|}{ s4 } & \multicolumn{3}{|c|}{ s5 } \\
\hline & c & $\mathrm{i}$ & d & c & $\mathrm{i}$ & $\mathrm{d}$ & c & $\mathrm{i}$ & $\mathrm{d}$ & c & $\mathrm{i}$ & d & c & $\mathrm{i}$ & $\mathrm{d}$ \\
\hline A & 66 & 18,6 & 8,3 & 40,7 & 28,4 & 30,9 & 75,3 & 13,8 & 10,9 & 35,2 & 33,6 & 31,2 & 36,4 & 27,9 & 35,6 \\
\hline B1 & 67,9 & 20,3 & 11,7 & 47,9 & 21,3 & 30,9 & 76,6 & 13,3 & 10,1 & 46,8 & 28,7 & 24,5 & 43,6 & 29,3 & 27,1 \\
\hline B2 & 75,8 & 16,8 & 7,4 & 63,5 & 19,6 & 16,9 & 84,2 & 8,4 & 7,4 & 47,9 & 28,9 & 23,2 & 47,9 & 20 & 32,1 \\
\hline $\mathrm{C}$ & 87,4 & 9,9 & 2,7 & 65,8 & 21,6 & 12,6 & 84,7 & 6,3 & 9 & 63,6 & 25,5 & 10,9 & 47,7 & 21,6 & 30,6 \\
\hline \multicolumn{16}{|l|}{ EM } \\
\hline S & 66 & 20,2 & 13,9 & 40,5 & 28,7 & 30,8 & 75,3 & 13,9 & 10,8 & 38,9 & 29,8 & 31,3 & 43,4 & 26,2 & 30,4 \\
\hline $\mathrm{M}$ & 73 & 17,2 & 9,8 & 57,4 & 21,6 & 21,1 & 82,8 & 10,3 & 6,9 & 46,1 & 31,4 & 22,5 & 45,1 & 27 & 27,9 \\
\hline F2 & 82,6 & 11,3 & 6,1 & 67,2 & 12,9 & 19,8 & 81,9 & 8,6 & 9,5 & 57,4 & 31,3 & 11,3 & 41,4 & 22,4 & 36,2 \\
\hline $\mathrm{F} 1$ & 80,9 & 14,3 & 4,8 & 65 & 20,5 & 14,5 & 83,3 & 6 & 10,7 & 56 & 25 & 19 & 38,1 & 21,4 & 40,5 \\
\hline \multicolumn{16}{|l|}{$\mathrm{P} \times \mathrm{E}$} \\
\hline AS & 65,4 & 19,4 & 15,2 & 38,9 & 27,8 & 33,3 & 74 & 14,2 & 11,8 & 38,4 & 29,8 & 31,8 & 41,5 & 27,3 & 31,1 \\
\hline $\mathrm{AM}$ & 67,7 & 19,8 & 12,5 & 46,9 & 24 & 29,2 & 79,2 & 11,5 & 9,4 & 36,5 & 39,6 & 24 & 39,6 & 32,3 & 28,1 \\
\hline $\mathrm{AB}$ & 73,5 & 18,4 & 8,2 & 66 & 14 & 20 & 80 & 14 & 6 & 58 & 26 & 16 & 28 & 28 & 44 \\
\hline BS & 69,8 & 25,6 & 4,6 & 51,2 & 34,9 & 14 & 83,7 & 11,6 & 4,7 & 41,9 & 30,2 & 27,9 & 55,8 & 18,6 & 25,6 \\
\hline $\mathrm{BM}$ & 77,8 & 14,8 & 7,4 & 66,7 & 19,4 & 13,9 & 86,1 & 9,3 & 4,6 & 54,6 & 24,1 & 21,3 & 50 & 22,2 & 27,8 \\
\hline $\mathrm{BB}$ & 84,7 & 10,7 & 4,7 & 66,4 & 16,8 & 16,8 & 83,3 & 5,3 & 11,3 & 56,4 & 29,5 & 14,1 & 44 & 20 & 36 \\
\hline G & 72,2 & 17,3 & 10,5 & 52,2 & 23,3 & 24,5 & 79,3 & 11,1 & 9,5 & 47,3 & 27,2 & 25,6 & 42,9 & 25,3 & 31,8 \\
\hline \multirow{2}{*}{ CLA } & \multicolumn{3}{|c|}{ s6 } & \multicolumn{3}{|c|}{ s7 } & \multicolumn{3}{|c|}{ s8 } & \multicolumn{3}{|c|}{ s9 } & \multicolumn{3}{|c|}{ s10 } \\
\hline & $\mathrm{c}$ & $\mathrm{i}$ & $\mathrm{d}$ & $\mathrm{c}$ & $\mathrm{i}$ & $\mathrm{d}$ & c & $\mathrm{i}$ & $\mathrm{d}$ & c & $\mathrm{i}$ & $\mathrm{d}$ & $\mathrm{c}$ & $\mathrm{i}$ & $\mathrm{d}$ \\
\hline A & 59,5 & 17,4 & 11,9 & 71,7 & 13 & 15,4 & 72,2 & 15,5 & 12,2 & 59,5 & 21,1 & 19,4 & 75,3 & 9,3 & 15,4 \\
\hline B1 & 69,1 & 12,8 & 18,1 & 75,9 & 14,4 & 9,6 & 77,7 & 13,8 & 8,5 & 53,2 & 29 & 17,7 & 81,4 & 9,6 & 9 \\
\hline B2 & 70,9 & 15,3 & 13,8 & 73,5 & 15,9 & 10,6 & 84,7 & 10 & 5,3 & 52,1 & 29,5 & 18,4 & 87,9 & 5,8 & 6,3 \\
\hline $\mathrm{C}$ & 73,9 & 13,5 & 12,6 & 71,2 & 18 & 10,8 & 82 & 12,6 & 5,4 & 51,4 & 32,4 & 16,2 & 92,8 & 4,5 & 2,7 \\
\hline \multicolumn{16}{|l|}{ EM } \\
\hline S & 61,1 & 16,3 & 22,6 & 72,8 & 13 & 14,2 & 73 & 16,1 & 10,9 & 56,1 & 23,9 & 20 & 77,7 & 8,4 & 13,9 \\
\hline $\mathrm{M}$ & 73 & 11,8 & 15,2 & 74 & 15,7 & 10,3 & 83,8 & 8,8 & 7,4 & 56,4 & 27,9 & 15,7 & 82,4 & 9,3 & 8,3 \\
\hline F2 & 68,7 & 18,3 & 13 & 71,6 & 14,7 & 13,8 & 81 & 14,7 & 4,3 & 55,2 & 27,6 & 17,2 & 87,9 & 6,9 & 5,2 \\
\hline F1 & 73,8 & 14,3 & 11,9 & 74,7 & 20,5 & 4,8 & 82,1 & 10,7 & 7,1 & 45,2 & 35,7 & 19 & 96,4 & 2,4 & 1,2 \\
\hline \multicolumn{16}{|l|}{$\mathrm{P} \times \mathrm{E}$} \\
\hline AS & 60,2 & 16,6 & 23,2 & 74 & 12,2 & 13,9 & 73,2 & 15,7 & 11,1 & 56,8 & 23,7 & 19,5 & 77,2 & 9 & 13,8 \\
\hline $\mathrm{AM}$ & 72,9 & 11,5 & 15,6 & 71,9 & 18,8 & 9,4 & 82,3 & 7,3 & 10,4 & 55,2 & 28,1 & 16,7 & 76 & 13,5 & 10,4 \\
\hline $\mathrm{AB}$ & 66 & 16 & 18 & 74 & 12 & 14 & 68 & 24 & 8 & 60 & 22 & 18 & 86 & 4 & 10 \\
\hline BS & 67,4 & 14 & 18,6 & 65,1 & 18,6 & 16,3 & 72,1 & 18,6 & 9,3 & 51,2 & 25,6 & 23,3 & 81,4 & 4,7 & 14 \\
\hline $\mathrm{BM}$ & 73,1 & 12 & 14,8 & 75,9 & 13 & 11,1 & 85,2 & 10,2 & 4,6 & 57,4 & 27,8 & 14,8 & 88 & 5,6 & 6,5 \\
\hline $\mathrm{BB}$ & 72,5 & 16,8 & 10,7 & 72,5 & 18,8 & 8,7 & 86 & 9,3 & 4,7 & 48 & 34 & 18 & 93,3 & 5,3 & 1,3 \\
\hline G & 67,1 & 15,1 & 17,8 & 73,2 & 14,9 & 12 & 78,3 & 13,2 & 8,4 & 54,8 & 27 & 18,3 & 82,7 & 7,7 & 9,5 \\
\hline
\end{tabular}

bons trabalhos, tem a maior parte das taxas de concordância um pouco superiores à metade da amostra.

Um terceiro padrão tem associação clara com as posições sociais, dizendo respeito à maior concordância por parte dos participantes dos estratos econômicos desfavorecidos e menor concordância dos estratos A e B1, que se reflete também na escolaridade da mãe, isto é, maior adesão às opiniões por parte de graus de escolaridade mais baixos e menor para participantes com mães mais escolarizadas. Isso é praticamente forte para os indicadores $s 2 \mathrm{e} s 4$, que dizem respeito à necessidade de obedecer normas e chefes. Por sua vez, o indicador $s 5$, que trata de "vestir a camisa", dedicar-se à organização de trabalho, para subir na carreira, tem as menores taxas de concordância. Participantes com posições sociais econômicas desfavo- 
ráveis tendem a aderir mais a esse ponto de vista que os das classes A e B1, mas para as duas modalidades de capital econômico, baixas escolaridades das mães associam-se a uma tendência menor a concordar com essa opinião. Finalmente, $s 1$, que enfatiza a importância de ideias para o progresso no trabalho, também tem mais concordância por parte das classes B2 e C, mas tem adesão de pelo menos dois terços dos ocupantes de todos os estratos.

A análise de correspondências múltiplas possibilita avaliar associações entre as respostas aos indicadores, e o faz tanto mais claramente quanto mais há desvios com relação aos perfis gerais da amostra. Há uma decomposição de todos os desvios em dimensões (ou eixos) de variação, de modo a identificar as principais combinações de modalidades dos indicadores - por exemplo, uma dimensão pode apresentar um padrão de resposta em que exista uma tendência maior dos participantes que responderam "concordo" a algum indicador em responderem "concordo" a algum outro, ou "discordo" a um terceiro.

As associações devem ser interpretadas relativamente ao padrão geral. Como novo exemplo, uma associação entre respostas de concordância a $s 2$ e $s 4$ traduz-se em que $65 \%$ dos que concordam com $s 2$ concordam também com $s 4$; isso é um desvio em relação ao perfil geral da amostra, em que, como mostra a Tabela 2, aproximadamente $52 \%$ da amostra concordam com $s 2$ e $47 \%$ com $s 4$. Logo, há atração entre essas duas modalidades avaliadas; as pessoas que optam pela concordância a $s 2$ têm tendência maior que a geral a concordar também com $s 4$. Cabe esclarecer que não é necessário um padrão majoritário para configurar associação; dos que discordam de $s 7$, aproximadamente $24 \%$ também discordam de $s 8$. Ainda assim, é uma proporção maior que as observadas na amostra geral, em que $12 \%$ que discordam de $s 7$ e $8 \%$ discordam de $s 8$.

Desse modo, a análise permite ir além da avaliação separada dos indicadores e avança na caracterização multivariada. Por fim, mesmo a análise sendo construída com base nas respostas aos indicadores, é possível projetar as posições das variáveis de capital econômico e cultural posteriormente, para tentar interpretar as diferenças dentro do quadro que proponho neste estudo. São as variáveis suplementares ou ilustrativas, que não participam da construção dos eixos - somente as variáveis dos indicadores são ativas, nesse caso -, mas ajudam a entender os resultados.
Cada dimensão tem um autovalor $(\lambda)$ que corresponde a uma proporção da inércia (ou variância) total dos dados das variáveis de indicadores. A análise permite representar numérica e graficamente as dimensões que descrevem os principais desvios, o que pode ser avaliado por essas proporções ( $\tau$ ). No caso da análise das correspondências múltiplas, a tabela indicadora que serve de base tem muitas dimensões, o que gera autovalores muito baixos e pouco diferenciados, que não dão boa apreciação dos padrões dos dados. É comum utilizar autovalores modificados $\left(\lambda^{\prime}\right)$ e taxas de inércia modificadas ( $\tau^{\prime}$ ), que dão ênfase aos autovalores com valores maiores que a média, com base numa fórmula de cálculo proposta por Benzécri (1992), apresentada também em LeRoux e Rouanet (2010, p. 39).

Para realizar a análise sem descartar casos com dados omissos, utilizei o algoritmo proposto especificamente para esse fim, implementado pelo pacote missmda e descrito por Josse e Husson (2016, p. 15-16). A vantagem está em utilizar somente os dados empíricos para calcular os resultados, ao mesmo tempo evitando perda de informação. Os autores ressaltam que o procedimento superestima um pouco a proporção de variância das dimensões, mas o baixo contingente de valores omissos implica distorção mínima.

A Tabela 3 traz os resultados numéricos da análise; as duas primeiras dimensões tiveram respectivamente $77 \%$ e $20 \%$ de proporções de inércia modificadas, o que indica que considerá-las cobre $97 \%$ desse índice, e que as demais dimensões apresentam desvios pouco importantes. A Figura 1 apresenta os mapas dos dois eixos correspondentes a essas duas dimensões, para as variáveis ativas (indicadores) e ilustrativas.

Para a interpretação da Tabela 3 e Figura 1, a coluna que diz respeito à coordenada no plano (Coord.) traz a posição nos eixos horizontal (Dim. 1) e vertical (Dim. 2). A contribuição para o fator (Ctr.) ou contribuição absoluta apresenta o percentual da inércia de cada dimensão que é composto por cada variável ativa, no caso, as modalidades das respostas aos indicadores ("concordo" - c, "indeciso" - i, e "discordo" - d). Conforme LeRoux e Rouanet (2010, p. 52), as modalidades importantes são as que excedem a média de contribuição para o fator. O cosseno quadrado $\left(\operatorname{Cos}^{2}\right)$, também chamado contribuição relativa, traz a informação do percentual da variável (ativa ou ilustrativa) explicada pela dimensão. Como aponta Greenacre (2007, p. 86-87), são correlações ao quadrado. A raiz quadrada do cosseno quadrado, precedida pelo sinal da coorde- 
Tabela 3

Resultados da Análise de Correspondências Múltiplas por Dimensão.

\begin{tabular}{|c|c|c|c|c|c|c|c|c|c|}
\hline \multirow{2}{*}{$\begin{array}{l}\text { Variável } \\
\text { Coord. }\end{array}$} & & \multicolumn{4}{|c|}{ Dimensão 1} & \multicolumn{4}{|c|}{ Dimensão 2} \\
\hline & & Ctr & $\mathrm{Cos}^{2}$ & $\eta^{2}$ & Coord. & Ctr & $\operatorname{Cos}^{2}$ & $\eta^{2}$ & \\
\hline \multirow[t]{3}{*}{ s1 } & sl_c & $-0,22$ & 1,41 & 0,12 & 0,13 & $-0,14$ & 0,87 & 0,05 & 0,15 \\
\hline & s1_i & 0,39 & 1,13 & 0,03 & & 0,84 & 7,11 & 0,15 & \\
\hline & sl_d & 0,84 & 3,07 & 0,08 & & $-0,4$ & 0,96 & 0,02 & \\
\hline \multirow[t]{3}{*}{ s2 } & s2_c & $-0,58$ & 7,36 & 0,37 & 0,4 & $-0,14$ & 0,63 & 0,02 & 0,21 \\
\hline & s2_i & 0,35 & 1,23 & 0,04 & & 0,8 & 8,71 & 0,2 & \\
\hline & s2_d & 0,9 & 8,28 & 0,26 & & $-0,45$ & 2,94 & 0,07 & \\
\hline \multirow[t]{3}{*}{ s3 } & s3_c & $-0,26$ & 2,25 & 0,26 & 0,27 & $-0,06$ & 0,15 & 0,01 & 0,17 \\
\hline & s3_i & 0,78 & 2,85 & 0,08 & & 1,04 & 6,96 & 0,13 & \\
\hline & s3_d & 1,25 & 6,27 & 0,17 & & $-0,74$ & 3,01 & 0,06 & \\
\hline \multirow[t]{3}{*}{ s4 } & s4_c & $-0,64$ & 7,99 & 0,36 & 0,43 & $-0,19$ & 1 & 0,03 & 0,27 \\
\hline & s4_i & 0,22 & 0,55 & 0,02 & & 0,82 & 10,71 & 0,25 & \\
\hline & s4_d & 0,94 & 9,5 & 0,3 & & $-0,52$ & 4,07 & 0,09 & \\
\hline \multirow[t]{3}{*}{ s5 } & s5_c & $-0,51$ & 4,76 & 0,2 & 0,23 & $-0,25$ & 1,56 & 0,05 & 0,2 \\
\hline & s5_i & 0,11 & 0,12 & 0 & & 0,76 & 8,55 & 0,2 & \\
\hline & s5_d & 0,61 & 4,95 & 0,17 & & $-0,27$ & 1,33 & 0,03 & \\
\hline \multirow[t]{3}{*}{ s6 } & s6_c & $-0,23$ & 1,49 & 0,11 & 0,11 & $-0,09$ & 0,31 & 0,02 & 0,14 \\
\hline & s6_i & 0,33 & 0,69 & 0,02 & & 0,83 & 6,14 & 0,12 & \\
\hline & s6_d & 0,58 & 2,55 & 0,07 & & $-0,37$ & 1,43 & 0,03 & \\
\hline \multirow[t]{3}{*}{ s7 } & s7_c & $-0,33$ & 3,34 & 0,3 & 0,34 & $-0,06$ & 0,14 & 0,01 & 0,18 \\
\hline & s7_i & 0,53 & 1,71 & 0,05 & & 0,88 & 6,7 & 0,14 & \\
\hline & s7_d & 1,36 & 9,33 & 0,25 & & $-0,75$ & 3,89 & 0,08 & \\
\hline \multirow[t]{3}{*}{ s8 } & s8_c & $-0,24$ & 1,94 & 0,21 & 0,24 & $-0,06$ & 0,16 & 0,01 & 0,14 \\
\hline & s8_i & 0,62 & 2,13 & 0,06 & & 0,84 & 5,44 & 0,11 & \\
\hline & s8_d & 1,28 & 5,81 & 0,15 & & $-0,76$ & 2,85 & 0,05 & \\
\hline \multirow[t]{3}{*}{ s9 } & s9_c & $-0,02$ & 0,01 & 0 & 0 & $-0,22$ & 1,51 & 0,06 & 0,13 \\
\hline & s9_i & $-0,05$ & 0,02 & 0 & & 0,59 & 5,46 & 0,13 & \\
\hline & s9_d & 0,14 & 0,15 & 0 & & $-0,22$ & 0,5 & 0,01 & \\
\hline \multirow[t]{3}{*}{ s10 } & s10_c & $-0,2$ & 1,43 & 0,2 & 0,22 & $-0,01$ & 0 & 0 & 0,12 \\
\hline & s10_i & 0,61 & 1,2 & 0,03 & & 0,96 & 4,17 & 0,08 & \\
\hline & s10_d & 1,27 & 6,46 & 0,17 & & $-0,7$ & 2,74 & 0,05 & \\
\hline \multirow[t]{4}{*}{ CLA } & A & 0,29 & - & 0,04 & 0,06 & $-0,02$ & - & 0 & 0 \\
\hline & B1 & 0,04 & - & 0 & & 0,05 & - & 0 & \\
\hline & B2 & $-0,23$ & - & 0,02 & & $-0,02$ & - & 0 & \\
\hline & $\mathrm{C}$ & $-0,32$ & - & 0,02 & & $-0,01$ & - & 0 & \\
\hline \multirow[t]{4}{*}{ EM } & S & 0,22 & - & 0,04 & 0,04 & 0 & - & 0 & 0 \\
\hline & $\mathrm{M}$ & $-0,15$ & - & 0,01 & & 0,01 & - & 0 & \\
\hline & F2 & $-0,18$ & - & 0,01 & & $-0,05$ & - & 0 & \\
\hline & F1 & $-0,26$ & - & 0,01 & & 0,03 & - & 0 & \\
\hline \multirow[t]{6}{*}{$\mathrm{P} \times \mathrm{E}$} & AS & 0,26 & - & 0,04 & 0,06 & $-0,01$ & - & 0 & 0 \\
\hline & $\mathrm{AM}$ & 0,05 & - & 0 & & 0,07 & - & 0 & \\
\hline & $\mathrm{AB}$ & 0 & - & 0 & & 0 & - & 0 & \\
\hline & BS & $-0,04$ & - & 0 & & 0,08 & - & 0 & \\
\hline & $\mathrm{BM}$ & $-0,32$ & - & 0,02 & & $-0,04$ & - & 0 & \\
\hline & $\mathrm{BB}$ & $-0,28$ & - & 0,02 & & $-0,03$ & - & 0 & \\
\hline \multirow{2}{*}{\multicolumn{2}{|c|}{$\begin{array}{l}\lambda\left(\lambda^{\prime}\right) \\
\tau\left(\tau^{\prime}\right)\end{array}$}} & \multicolumn{4}{|c|}{$0,239(0,024)$} & \multicolumn{4}{|c|}{$0,171(0,006)$} \\
\hline & & \multicolumn{4}{|c|}{$0,12(0,77)$} & & & & \\
\hline
\end{tabular}



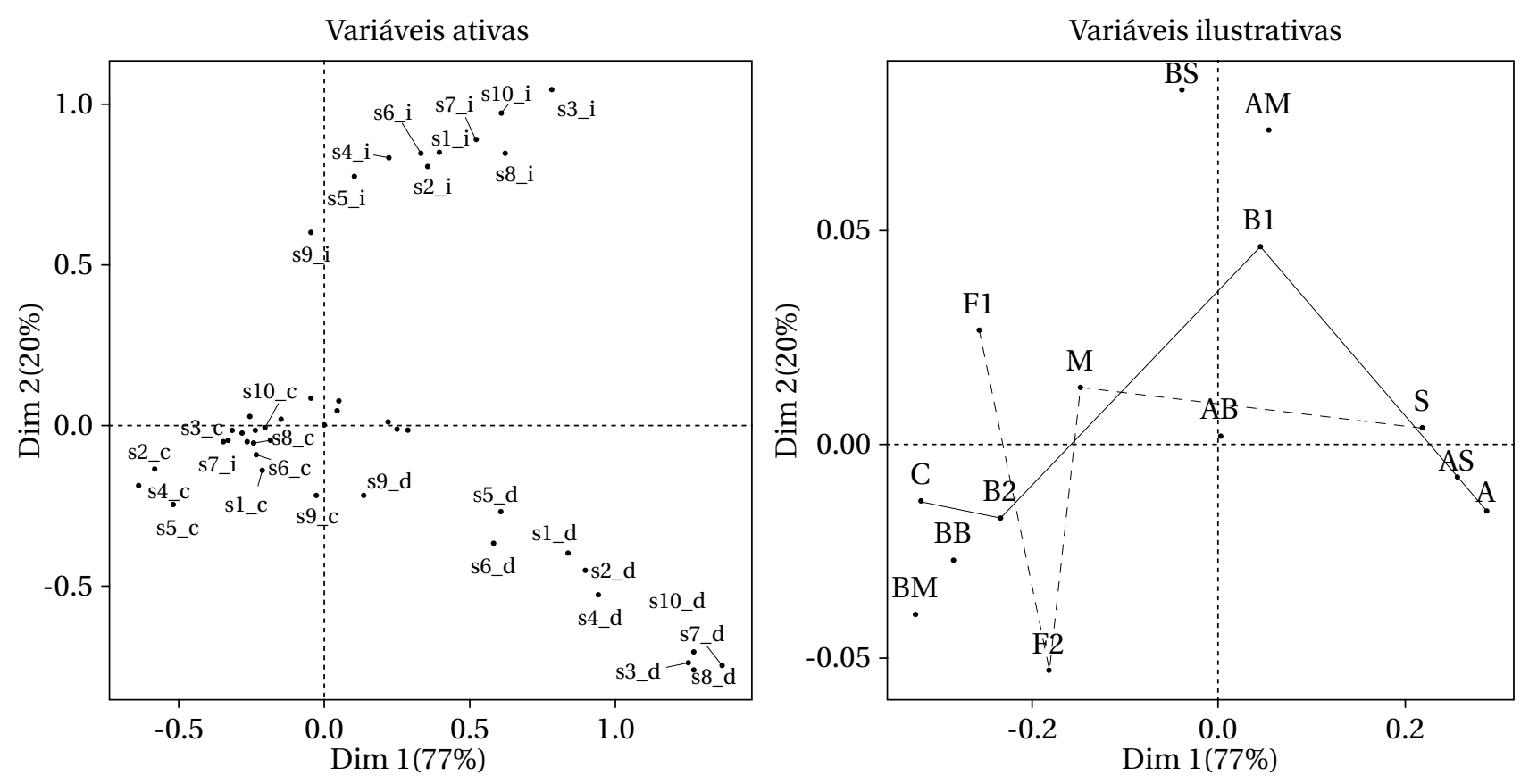

Figura 1

Mapas referentes às variáveis ativas e ilustrativas da análise de correspondências múltiplas.

nada na dimensão, pode ser interpretada como a carga fatorial nas análises fatoriais.

A qualidade da representação num plano fatorial é dada pela soma dos cossenos quadrados das dimensões ali representadas: quanto maior, mais segurança para interpretar distâncias. Por fim, o eta-quadrado $\left(\eta^{2}\right)$ ou razão de correlações equivale à razão entre as variâncias das médias dos pontos de cada modalidade e a variância total dos pontos de todas as modalidades (LeRoux, \& Rouanet, 2004). É a correlação ao quadrado entre cada indicador ou variável suplementar e as dimensões, e indica a proporção da variância dessas variáveis que é explicada por cada dimensão.

No caso da análise relatada, há 30 modalidades de resposta e, dividindo-se 100 (percentual total) por 30, o resultado é que a contribuição média é de 3,33; logo, contribuições de 3,34 ou mais são consideradas mais relevantes para determinar cada dimensão. A primeira dimensão, eixo horizontal da Figura 1, recebe contribuições importantes principalmente das respostas de concordância aos indicadores $s 4, s 2$ e $s 5$, e das respostas de discordância a esses indicadores, bem como a $s 3$, $s 7, s 8$ e $s 10$. Ou seja, há um desvio do perfil geral, com pessoas que tendem a concordar com pontos de vista que sustentam que a obediência a normas e chefes e dedicação à empresa levam ao sucesso no trabalho, e as que discordam desse ponto de vista e também de opiniões de crença na vigência da meritocracia no trabalho. Os resultados indicam tendência dessas pessoas de endossarem essas modalidades presentes em cada polo da dimensão simultaneamente. Chamemos esses perfis, respectivamente, de "crentes na hierarquia e meritocracia" e "céticos da meritocracia".

O exame das variáveis ilustrativas permite interpretar se existe alguma associação dos indivíduos classificados desse modo com as variáveis de posição social. A parte direita da Figura 1 traz uma ampliação da zona central da parte esquerda da Figura; por ali é possível observar que a dispersão das modalidades suplementares é consideravelmente menor que a das variáveis ativas. Isso também fica claro nos valores bem mais modestos de cossenos quadrados, indicando baixas correlações das variáveis ilustrativas, de posição social, com os eixos. Mesmo assim, há uma variação no decorrer do eixo horizontal. Indivíduos do estrato econômico A situam-se no polo dos céticos na meritocracia, enquanto que os dos estratos B2 e C colocam-se no lado dos crentes. Conforme LeRoux e Rouanet (2010, p. 59), diferenças nas coordenadas entre categorias maiores que 0,5 são importantes, e a diferença de A para B2 e C é superior a isso. Por outro lado, a categoria B1 encontra-se em posição 
intermediária, próxima da origem ou perfil médio. No que diz respeito à escolaridade da mãe, as diferenças são menores, mas opõem os participantes com mãe com nível superior no lado dos céticos e as mães com os outros níveis de escolaridade, inferiores, no lado dos crentes. Finalmente, considerando a variável de posição social que combina os capitais econômico e cultural, há um contraste mais pronunciado entre participantes com os dois capitais em níveis elevados - céticos - e aqueles com baixo capital econômico e escolaridade da mãe nos níveis médio e baixo. As demais categorias situam-se próximas à origem.

Um exame da segunda dimensão aponta que se trata de uma dimensão menos interessante para os objetivos do estudo; as categorias que contribuem para a dimensão correspondem às respostas de indecisão de todos os indicadores, e, em menor nível, discordância de $s 4$ e $s 7$. Os cossenos quadrados também indicam representação inferior. Em síntese, o eixo aponta a tendência de os indivíduos que se mostraram indecisos ao responder a indicadores sobre meritocracia, hierarquia e sucesso no trabalho optarem por respostas de indecisão também nos outros indicadores. Esse perfil se opõe aos participantes que discordam de que a obediência aos chefes leva ao reconhecimento no trabalho e que o trabalho duro é reconhecido. Quanto às variáveis ilustrativas, as coordenadas são muito próximas da origem, indicando que são mal explicadas pela dimensão.

\section{Discussão}

Uma interpretação dos resultados de frequência aponta que a visão meritocrática do sucesso no trabalho, isto é, de que a explicação para a obtenção de empregos com bons salários ou promoções no trabalho se dá por meio de variáveis ligadas ao desempenho individual, é a que mais se aproxima de consenso na amostra, com altas proporções de concordância. A formação de um consenso ou algo próximo disso fortalece muito as ideologias, uma vez que elas deixam de lado o terreno da disputa de opiniões ou pontos de vista para se tornarem, para a sociedade que sustenta o consenso, equivalentes em potencial de verdades objetivas. Uma opinião consensual ou amplamente majoritária constitui um fato social que, se não é incontestável, é uma percepção do mundo social que demanda um trabalho muito forte de questionamento, tendo em vista seu amplo respaldo na população. Se esse consenso for manifesto, isto é, se os membros de uma sociedade ou grupo concordam em relação a algum assunto e simultaneamente são conscientes dessa concordância (nos moldes de Moliner, 2001), uma opinião poderia assumir, para uma dada comunidade, o estatuto próximo de um fato reconhecido, que não admite divergência. Nos termos da teoria da elaboração do conflito de Pérez e Mugny (1993) e dos estudos empíricos a ela relacionados, quando se trata de uma situação em que a expectativa é de consenso, a percepção de existência de uma maioria é um fator que tem efeitos poderosos para coibir dissidências explícitas (comportamentais) ou latentes (em termos de posições pessoais), exercendo pressão para que as pessoas se conformem. Por outro lado, numa situação em que se esperam posições divergentes ou opiniões, a pluralidade passa a ser considerada uma possibilidade, e isso permite influência de diversos pontos de vista.

A conversão de uma opinião em consenso cultural reflete o sucesso do trabalho ideológico, o que é propiciado pela ação convergente de uma série de instâncias, como a socialização inicial, de caráter afetivo, nas famílias, conforme descrito por Berger e Luckmann (2003); a inculcação de conteúdos culturais a partir de instituições pedagógicas que gozam de legitimidade social, como na teoria da reprodução de Bourdieu e Passeron (2013); e estratégias e fenômenos de comunicação de massa voltados para o consenso, como o estabelecimento de pautas de discussão social por meio das empresas de mídia (McCombs, \& Shaw, 1972) e a tendência à supressão de opiniões divergentes da maioria (Noelle-Neumann, 1995). A transformação de uma opinião, evidentemente arbitrária, em fato reconhecido, oculta sua origem social e a possibilidade de conceber posições alternativas, o que dificulta o combate à ideologia, tornando-a mais resistente.

Analisando além das tendências de consenso sobre a meritocracia, as diferenças mais pronunciadas entre posições sociais estão nos indicadores da necessidade de submeter-se à hierarquia das empresas e chefes, posição majoritária entre estratos econômicos e de escolaridade desfavoráveis e com menor adesão por parte dos estratos favoráveis. Mas como explicar que os estudantes de condições sociais desfavoráveis tendem a aderir mais a opiniões que defendem a obediência a normas e patrões, uma vez que é mais provável que eles ocuparão posições subordinadas no futuro, isto é, exatamente aquelas que deverão obedecer e seguir as regras? Não seria mais lógico imaginar que a projeção dos trabalhos futuros os levasse a desafiar a hierarquia, buscando maior protagonismo? 
A teoria da justificação do sistema, formulada por John Jost e Mazharin Banaji (Jost, \& Banaji, 1994) e que tem suporte em diversos estudos empíricos (a esse respeito, ver Jost, Banaji, \& Nosek, 2004), explica que as pessoas tendem a justificar o estado das coisas na sociedade, por mais que ele seja injusto; seria uma tendência a considerar a ordem social como boa, justa e inevitável, mesmo que elas estejam objetivamente em más condições de vida e possam beneficiar-se de mudanças nos sistemas sociais. Trata-se então de um fenômeno psicológico nitidamente alinhado com funções ideológicas, à medida em que se busca legitimar a realidade e isso contribui para sua conservação. Jost e Hunyady (2002) sugerem que a motivação para justificar condições desfavoráveis para sua posição social permite lidar com situações de privação que parecem inevitáveis, paradoxalmente dando algum conforto às pessoas; é como se os ocupantes de posições sociais desfavoráveis, que de qualquer maneira não dispõem de meios para alterar substancialmente suas condições de vida em virtude do baixo capital e ausência de controle sobre instâncias políticas decisórias, preferissem tranquilizar-se acreditando que seus problemas não decorrem de injustiças arbitrárias. Constatar a dificuldade de lidar com um sistema injusto poderia levar a sentimentos de ansiedade e desesperança. Em virtude da penetração de ideologias e sua aceitação, as pessoas buscariam justificar o estado das coisas para lidar com aquilo que não conseguem mudar. Tanto os resultados consensuais referentes aos estudantes do presente estudo de acordo sobre a vigência da meritocracia quanto a maior adesão a opiniões reconhecendo a necessidade de obediência às normas são compatíveis com o fenômeno da justificação do sistema.

Outra maneira de interpretar essa adesão à meritocracia mesmo em uma posição desvantajosa diz respeito à avaliação da liberdade de escolha por parte dos ocupantes dessas posições, ou melhor, à restrição de escolhas. Sem capital econômico e cultural, um trabalhador dispõe de que possibilidades para ter um emprego bem remunerado ou desafiar chefes e normas de uma organização? Salvo exceções, que constituem narrativas interessantes e vívidas exatamente por serem surpreendentes e sobrepujarem expectativas, a maior parte das pessoas nessa situação precisa submeter-se à oferta de baixos salários e condições impostas pelo mercado de trabalho. Não há margem para jogar o jogo de modo diferente, sob pena de dispensa. Nesse contexto específico, o traba- lhador precisa seguir as regras que lhe são apresentadas para manter-se empregado e avalia, racional e corretamente, que suas chances de sucesso no trabalho estarão vinculadas ao respeito a essas condições. Uma interpretação assim não se explica por um desejo de evitar a dureza da realidade, mas sim pelo entendimento de que as boas posições de trabalho não são acessíveis, e dentro das possibilidades que se apresentam aos ocupantes de posições sociais desfavoráveis, a sobrevivência está associada ao respeito àqueles que controlam seus destinos.

Chama a atenção também o efeito conjunto das variáveis de renda e escolaridade da mãe. De modo geral, as duas parecem amplificar os efeitos uma da outra; um participante com alta renda e com mãe com alto nível de escolaridade tende a alinhar-se de modo mais forte com os padrões de resposta observados para as duas posições, enquanto que os estudantes de estrato econômico desfavorável e com mães com poucos anos de estudo localizam-se no outro extremo. Já a escolaridade intermediária apresenta resultados mais complexos, de interpretação mais difícil ora mostrando proporções próximas às de participantes com mãe com alta ou baixa escolaridade.

Para os indicadores de opinião de obediência a chefes e normas de empresa, a escolaridade materna é um aspecto importante para entender as tendências dos resultados. É como se a escolaridade materna, para esses assuntos, quando em nível elevado ou baixo, compensasse as diferenças culturais associadas à renda familiar e conduzisse os participantes com posições divergentes nas duas dimensões de capital (isto é, alto econômico e baixo cultural e vice-versa) a uma percepção direcionada pela modalidade de escolaridade, ou seja estudantes de boa condição econômica que carregam consigo uma leitura subordinada da relação com normas e patrões, e estudantes empobrecidos que dispõem de uma grade de leitura dessa realidade equivalente ao dos estudantes de melhor condição econômica.

Para Flyvbjerg (2001), as ciências sociais não teriam por objetivo principal o desenvolvimento de teorias, mas a análise das situações sociais de modo a contribuir para sua avaliação crítica dos rumos delineados para o futuro, visando à ação e tomada de decisão em benefício da população. Nessa perspectiva, é necessário pensar a respeito das implicações dos consensos observados, ou mais especificamente da adesão significativa dos estratos mais desfavorecidos aos temas de apoio à meritocracia e individua- 
lismo quanto à necessidade de respeito à autoridade, na esfera do sucesso no trabalho. Como se trata de integrantes dos setores sociais em desvantagem, a garantia de sua conformidade assegura a ordem social com que, de acordo com a interpretação de Darcy Ribeiro (2006, p. 20-23), as classes dominantes preocupam-se obsessivamente. Se os próprios ocupantes de estratos de renda inferiores - noutros termos, as classes dominadas - subscrevem às opiniões ideológicas avaliadas na pesquisa aqui relatada, opiniões essas que legitimam princípios que favorecem as pessoas com mais capital a manterem ou melhorarem sua posição socioeconômica, já que dispõem de preparação e recursos mais adequados para competir por postos de trabalho valorizados, então há uma indicação do sucesso do trabalho de disseminação e sustentação ideológica realizado pelas diversas instâncias de socialização, como família, escola, mídia e outras.

Mesmo que os resultados referentes aos estratos de renda elevada não indiquem apoio a algumas das crenças sobre hierarquia, isso não ameaça o sistema social de distribuição de capital. Afinal, contradição ou percepção de ilegitimidade não parecem presentes nas opiniões dos indivíduos dos estratos de renda inferior, inibindo tendências de mudança ou questionamento. $\mathrm{O}$ amplo consenso encontrado é possivelmente uma evidência do sucesso da inculcação da ideologia liberalista, calcada em pilares como o individualismo e a competição. Isso configura um quadro próximo ao que Gramsci (1971) chamaria de hegemonia cultural, haja vista que os vários grupos e classes sociais parecem reconhecer e aceitar princípios que, em última instância, favorecem os grupos e classes sociais em posições privilegiadas.

\section{Considerações finais}

Em síntese, o consenso interclasses sobre a percepção de que a meritocracia é o princípio vigente para determinação da quantidade de recursos (capital) que cabe aos integrantes da sociedade implica uma naturalização dessa ideologia. A respeito desse processo de naturalização, levanto a necessidade de estudá-lo futuramente especialmente no que diz respeito à produção da percepção de que certas maneiras de pensar sejam consideradas verdades fatuais, central para explicar a equivalência da ideologia a algo próximo da verdade. Essa análise deverá certamente levar em consideração o papel da comunicação social para a construção de uma atmosfera favorável a esse entendimento. Por sua vez, a consolidação da ideologia meritocrática como algo consensual retira das pessoas que estão na sociedade e que não dispõem de capital a possibilidade de identificar modos alternativos de funcionamento da sociedade. Isso, juntamente com a consciência da própria situação precária, pode explicar a aceitação por parte das pessoas de estratos de renda inferiores da necessidade de obedecer superiores e normas de empresas. Trata-se de um misto de entendimento do próprio lugar social com domesticação derivada do consenso ideológico.

Em termos das limitações do estudo apresentado, é necessário ressaltar que, mesmo se os resultados e interpretações oferecidos nesta pesquisa junto a estudantes de Uberlândia se mostrem pertinentes para outros contextos no Brasil, a pesquisa não tem pretensões de generalização estatística, restringindo-se à interpretação de análises descritivas para a amostra estudada. Não utilizar a estatística inferencial é uma escolha pela compreensão do contexto particular associado à pesquisa, cuja natureza exploratória deve ser novamente ressaltada.

Finalmente, especialmente na seção de discussão, busquei argumentar conforme as interpretações que me pareceram mais sensatas e condizentes com os resultados, mas certamente há restrições de minha compreensão, pelas quais me responsabilizo totalmente. Outros avaliarão os dados a partir de outras perspectivas, propondo explicações alternativas.

\section{Referências}

Althusser, L. (1996). Ideologia e aparelhos ideológicos de Estado. In S. Žižek (Org.), Um mapa da ideologia (Vera Ribeiro, Trad., pp. 105-142). Rio de Janeiro, RJ: Contraponto.

Associação Brasileira de Empresas de Pesquisa - ABEP. (2013). Critério de Classificação Econômica Brasil:alterações na aplicação do Critério Brasil, válidas a partir de 01/01/2013. Recuperado de http://www.abep.org/Servicos/ download.aspx?id=02

Benzécri, J.-P. (1992). Correspondence analysis handbook. New York, NY: Dekker. 
Berger, P. L., \& Luckmann, T. (2013). A construção social da realidade: tratado de sociologia do conhecimento (Floriano de Souza Fernandes, Trad.). Petrópolis, RJ: Vozes.

Bourdieu, P. (1977). Sur le pouvoir symbolique. Annales. Économies, Sociétés, Civilisations, 32(3), $405-411$.

Bourdieu, P. (1986). The forms of capital. In J. Richardson (Org.), Handbook of theory and research for the sociology of education (pp. 241-258). Westport, CO: Greenwood.

Bourdieu, P., \& Passeron, J.-C. (2013). A reprodução: elementos para uma teoria do sistema de ensino (6a ed., Reynaldo Bairão, Trad.). Petrópolis, RJ: Vozes.

Buchmann, C. (2002). Measuring family background in international studies of education: conceptual issues and methodological challenges. In A. Porter, \& A. Gamoran (Orgs.), Methodological advances in cross-national surveys of educational achievement (pp. 150-197). Washington, D. C.: National Academy Press.

De Tracy, A. D. (1801). Projet d'éléments d'idéologie: a l'usage des écoles centrales de la Republique Française. Paris: Pierre Didot.

Flyvbjerg, B. (2001). Making social science matter: why social inquiry fails and how it can succeed again. Cambridge: Cambridge University Press.

Gerring, J. (1997). Ideology: a definitional analysis. Political Research Quarterly, 50(4), 957-994. https://doi.org/10.1177/106591299705000412

Gramsci, A. (1971). Selections from the prison notebooks. (Quintin Hoare, \& Geoffrey Nowell Smith, Trad.). New York: International Publishers.

Greenacre, M. (2007). Correspondence analysis in practice (2a ed.). Boca Raton: Chapman \& Hall.

Instituto Brasileiro de Geografia e Estatística (2017). Indicadores IBGE. Pesquisa Nacional por Amostra de Domicílios Contínua: primeiro trimestre de 2017. Recuperado de ftp://ftp.ibge.gov.br/Trabalho_e_Rendimento/Pesquisa_ Nacional_por_Amostra_de_Domicilios_continua/Trimestral/Fasciculos_Indicadores_IBGE/pnadc_201701_trimestre_caderno.pdf

Josse, J., \& Husson, F. (2016). missMDA: a package for handling missing values in multivariate data analysis. Journal of Statistical Software, 70(1), 1-31. https://doi.org/10.18637/jss.v070.i01

Jost, J., \& Banaji, M. R. (1994). The role of stereotyping in system-justification and the production of false consciousness. British Journal of Social Psychology, 33(1), 1-27. https://doi.org/10.1111/j.2044-8309.1994.tb01008.x

Jost, J. T., Banaji, M. R., \& Nosek, B. A. (2004). A decade of system-justification theory: accumulated evidence of conscious and unconscious bolstering of the status quo. Political Psychology, 25(6), 881-919. https://doi.org/10.1111/j.1467-9221.2004.00402.x

Jost, J. T., \& Hunyady, O. (2002). The psychology of system justification and the palliative function of ideology. European Review of Social Psychology, 13, 111-153. https://doi.org/10.1080/10463280240000046

Kassambara, A., \& Mundt, F. (2016). factoextra: extract and visualize the results of multivariate data analysis. $R$ package version 1.0.3. Recuperado de https://CRAN.R-project.org/package=factoextra

Lê, S., Josse, J., \& Husson, F. (2008). FactoMineR: an R package for multivariate analysis. Journal of Statistical Software, 25(1), 1-18. https:// doi.org/10.18637/jss.v025.i01

Le Roux, B., \& Rouanet, H. (2004). Geometric data analysis: from correspondence analysis to structured data analysis. Dordrecht: Kluwer.

Le Roux, B., \& Rouanet, H. (2010). Multiple correspondence analysis. Thousand Oaks, CA: Sage.

Mannheim, K. (1987). Ideología y utopia. Introducción a la sociología del conocimiento ( 2a ed., Salvador Echavarria, Trad.). Cidade do México, D. F. : Fondo de Cultura Económica.

Marx, K. (1996). O capital: crítica da economia politica (Vol. 1, Regis Barbosa \& Flávio R. Kothe, Trad.). São Paulo, SP: Nova Cultural.

Marx, K., \& Engels, F. (2009). A ideologia alemã (Álvaro Pina, Trad.). São Paulo, SP: Expressão Popular.

McCombs, M., \& Shaw, D. L. (1972). The agenda-setting function of mass media. Public Opinion Quarterly, 36(2), 176-187. https://doi.org/10.1086/267990 
Moliner, P. (2001). Consensus manifestes, consensus latents et consensus illusoires. Cahiers Internationaux de Psychologie Sociale, 49, 114-122.

Noelle-Neumann, E. (1995). La espiral del silencio: opinión pública: nuestra piel social (Javier Ruiz Calderón, Trad.). Madrid: Paidos.

Oliveira, D. C., Fischer, F. M., Amaral, M. A., Teixeira, M. C. T. V., \& Sá, C. P. (2005). A positividade e a negatividade do trabalho nas representações sociais de adolescentes. Psicologia Reflexão e Crítica, 18(1), 125-133. https:// doi.org/10.1590/S0102-79722005000100017

Pérez, J. A., \& Mugny, G. (1993). Influences sociales: la théorie de l'élaboration du conflit. Neuchâtel: Delachaux et Niestlé. Pochmann, M. (2012). Nova classe média? O trabalho na base da pirâmide social brasileira. São Paulo, SP: Boitempo.

Pochmann, M., Amorim, R. L. C., Guerra, A., \& Aldrin, R. (Orgs.). (2009). Atlas da nova estratificação social no Brasil (Vol. 3. Proprietários: concentração e continuidade). São Paulo, SP: Cortez.

R Core Team (2015). R: a language and environment for statistical computing. Viena: R Foundation for Statistical Compuing.

Ribeiro, C. A. C. (2011). Desigualdade de oportunidade e resultados educacionais no Brasil. Dados, 54(1), 41-87. https://doi.org/10.1590/S0011-52582011000100002

Ribeiro, D. (2006). O povo brasileiro: a formação e o sentido do Brasil. São Paulo, SP: Companhia de Bolso.

Robette, N. (2014). GDAtools: a toolbox for the analysis of categorical data in social sciencse. R package version 1.3. Recuperado de https://CRAN.R-project.org/package=GDAtools

Sobrosa, G. M. R., Camerin, C., Perrone, C. M., \& Dias, A. C. G. (2013). Opiniões sobre trabalho em jovens de classes populares. Revista Brasileira de Orientação Profissional, 14(2), 265-276. Recuperado de http://pepsic.bvsalud. org/scielo.php?script=sci_arttext\&pid=S1679-33902013000200011

Sørensen, A. B. (2005). Foundations of a rente-based class analysis. In E. O. Wright (Org.), Approaches to class analysis (pp. 119-151). New York, NY: Cambridge University Press.

Thomé, L. D., Telmo, A. Q., \& Koller, S. H. (2010). Inserção laboral juvenil: contexto e opiniões sobre definições de trabalho. Paidéia (Ribeirão Preto), 20(46): 175-185. https://doi.org/10.1590/S0103-863X2010000200005

Thompson, J. B. (2011). Ideologia e cultura moderna. Teoria social crítica na era dos meios de comunicação de massa (9a ed., Grupo de Estudos sobre Ideologia, Comunicação e Representações Sociais da Pós-Graduação do Instituto de Psicologia da PUCRS, Trad.). Petrópolis, RJ: Vozes.

Wright, E. O. (Org.). (2005). Approaches to class analysis. New York, NY: Cambridge University Press.

Žižek, S. (1996). O espectro da ideologia. In S. Žižek (Org.), Um mapa da ideologia (pp. 7-38, Vera Ribeiro, Trad.). Rio de Janeiro, RJ: Contraponto.

\section{João Wachelke}

Doutorado em Psicologia Sociale e della Personalità pela Università degli Studi di Padova, Itália (2011). Professor adjunto da Universidade Federal de Uberlândia, Brasil. E-mail: joao.wachelke@ufu.br

Endereço para envio de correspondência:

Universidade Federal de Uberlândia. Campus Umuarama,

Bloco 2C, Sala 34. Av. Pará, 1720, Uberlândia - MG, CEP 38400-902.

Recebido 01/11/2016

Aprovado 02/08/2017

Received 11/01/2016

Approved 08/02/2017 
Psicologia: Ciência e Profissão Jul/Set. 2017 v. 37 n³, 652-668.

Recebido 01/11/2016

Aceptado 02/08/2017

Como citar: Wachelke, J. (2017). Ideologia nas opiniões de estudantes de ensino médio sobre sucesso no trabalho. Psicologia: Ciência e Profissão, 37(3), 652-668. https:// doi.org/10.1590/1982-3703004062016

How to cite: Wachelke, J. (2017). Ideology in the opinions of secondary school students on success at work. Psicologia: Ciência e Profissão, 37(3), 652-668. https:// doi.org/10.1590/1982-3703004062016

Cómo citar:Wachelke, J. (2017). La ideología en las opiniones de estudiantes de secundaria acerca del éxito en el trabajo. Psicologia: Ciência e Profissão, 37(3), 652-668. https://doi.org/10.1590/1982-3703004062016 